\title{
Towards Carbon Neutrality in Higher Education Institutions: Case of Two Private Universities in Colombia
}

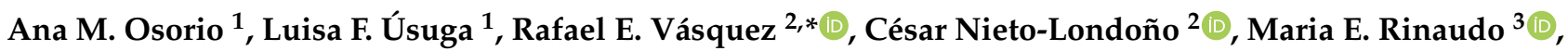 \\ José A. Martínez ${ }^{4}$ (D) and Walter Leal Filho ${ }^{5,6}$ (D) \\ 1 Sustainability Program, Universidad Pontificia Bolivariana, Medellín 050031, Colombia; \\ ana.osoriof@upb.edu.co (A.M.O.); luisafernanda.usuga@upb.edu.co (L.F.Ú.) \\ 2 School of Engineering, Universidad Pontificia Bolivariana, Medellín 050031, Colombia; \\ cesar.nieto@upb.edu.co \\ 3 Institute for Sustainable Entrepreneurship, Universidad Ean, Bogotá 110221, Colombia; \\ merinaudo@universidadean.edu.co \\ 4 Faculty of Engineering, Universidad Ean, Bogotá 110221, Colombia; jamartinez@universidadean.edu.co \\ 5 European School of Sustainability Science and Research, Hamburg University of Applied Sciences, \\ Ulmenliet 20, D-21033 Hamburg, Germany; walter.leal2@haw-hamburg.de \\ 6 Department of Natural Sciences, Manchester Metropolitan University, Chester Street, \\ Manchester M1 5GD, UK \\ * Correspondence: rafael.vasquez@upb.edu.co; Tel.: +57-604-4488388 (ext. 14165)
}

Citation: Osorio, A.M.; Úsuga, L.F.; Vásquez, R.E.; Nieto-Londoño, C.; Rinaudo, M.E.; Martínez, J.A.; Leal Filho, W. Towards Carbon Neutrality in Higher Education Institutions: Case of Two Private Universities in Colombia. Sustainability 2022, 14 , 1774. https://doi.org/10.3390/ su14031774

Academic Editors: Maki Ikegami and Iain Patton

Received: 22 September 2021 Accepted: 14 December 2021 Published: 4 February 2022

Publisher's Note: MDPI stays neutral with regard to jurisdictional claims in published maps and institutional affiliations.

Copyright: (c) 2022 by the authors. Licensee MDPI, Basel, Switzerland. This article is an open access article distributed under the terms and conditions of the Creative Commons Attribution (CC BY) license (https:// creativecommons.org/licenses/by/ $4.0 /)$.
Abstract: This paper addresses the path followed by two private higher education institutions (HEI) in Colombia towards achieving carbon neutrality. The methodology followed by these universities to achieve a carbon-neutral certification, based on the Greenhouse Gas (GHG) Protocol, is first described. The process of developing the GHG inventory, projected towards the carbon neutrality of these organisations while using the standard ISO 14064:2006, involved a series of steps that were consolidated in three phases: (i) definition of the scope, collection of data and emissions quantification; (ii) analysis of results and mitigation actions; and (iii) verification and compensation strategies. Results for the HEIs are shown in terms of the organisational context, carbon footprint measurement, reduction, verification, and compensation. The case is presented for Universidad Pontificia Bolivariana, a multi-campus university that became the first carbon-neutral university in Latin America in 2017, and Universidad Ean, a single-campus university that became the second carbon-neutral university in Colombia in 2021, as verified by the Colombian Institute of Technical Standards and Certification (ICONTEC). This work shows that universities can play a key role in regional and global agendas with their contribution through the incorporation of sustainability strategies, since HEIs can not only achieve carbon neutrality, but they can help other organisations by delivering graduates who are aware of sustainability and provide specific training towards building a sustainability culture, which is needed for regenerative development.

Keywords: carbon footprint; higher education institutions; sustainability; carbon neutrality; sustainable development; regenerative development

\section{Introduction}

The fulfilment of the 2030 Agenda, as defined by the United Nations in 2015 [1] through the Sustainable Development Goals (SDGs), requires the implementation of policies from different dimensions of sustainability, which implies efforts and actions to be performed by several sectors and actors around the world to achieve a high quality of life, while staying within planetary boundaries [2]. Regarding the environmental dimension, different indicators and tools to assess such boundaries have been proposed [3]. Tools from this dimension have been used as references to develop new SDG-based sustainability assessment models for several economic sectors [4], leading, for instance, to the development of new policies and practices in the Global South [5]. Although the concept of sustainable development exists since the 1980s, the SDGs have been adopted as a 
consensus normative framework that represents a game-changer when refereeing such a concept [6]. In connection with this, cities have become crucial for the survival of humanity as spaces adaptation and sustainability [7], therefore, globally-debated principles such as the ones within the SDGs, must be connected with local engaged practices, supported by indicators and evidence-based policies that have been built on well known frameworks [7,8]. In the case of education, the 2030 Agenda has been seen as a scenario to engage higher education institutions (HEIs), as spaces for adaptation and sustainability within cities, with responsible management of education to make a more significant contribution to the social good [9]. It is possible to find several studies that exemplify how HEIs can play a pivotal role in the implementation of the SDGs [10,11] while transforming curricula, learning experiences, research goals, campus operations, and strengthening partnerships to address the Agenda 2030 [12].

Regarding sustainability in HEIs, one can find numerous examples of efforts that have been reported from several countries, including, for instance: the United States and Canada [13,14], Italy [15], Ecuador [16], Portugal [17], Brazil [18,19], Turkey [20], Jordan [21], and Colombia [22], among others. At the end of the first decade of 2000, Rauch and Newman [23] derived a qualitative/quantitative methodology to define what a sustainable metric target might be and how it can be used to describe the path for universities towards sustainability, using short to long-term time scales. Then, in the middle of the 2010s, Amaral et al. [24] presented a review of methods and approaches that universities had used to implement, assess, and report sustainability. More recently, Leal Filho et al. [25] explored difficulties and potentials for planning sustainable development in higher education by promoting the integration of economic development, social development, and environmental protection at HEIs. Vargas et al. [26] presented a study that showed that sustainability processes grow over time at HEIs in four stages: emergence, popularisation, formalisation, and maturity, with increasing interactions between society, industry and academia. Leal Filho et al. [27] performed an international study with 70 HEIs and showed the relevance of green and sustainability offices as key structures and effective tools in pursuing and implementing sustainability goals. Regarding the environmental dimension of sustainability, Roos and Guenther [28] provided an overview of the environmental management performance in HEIs and proposed a model for structuring environmental sustainability efforts, which nowadays include, for example, defining the path towards carbon neutrality.

Concerns and initiatives to reach carbon neutrality started several years ago [29], and several studies have reported on this matter for HEIs during the last five years. O'Hara and Sirianni [30] said that the American College and University Presidents' Climate Commitment (ACUPCC) initiative declared carbon neutrality as a goal for 152 institutions, as agreed upon in 2007. Jain et al. [31] presented a framework called Carbon Neutrality and Sustainability in Educational Campuses (CaNSEC) and used it to assess TERI University in India. Fonseca et al. [32] designed a renovation plan for a campus building to achieve nearly zero energy performance. Udas et al. [33] reported a case study from the University of Greifswald in Germany that addressed the path towards a carbon-neutral university. Yangka et al. [34] presented the methodology followed by the University of California, Davis, which is used to identify equipment, capacities, and technical and economic factors influencing the implementation of a carbon-neutral energy system. More recently, Auger et al. [35] presented a carbon footprint estimator regarding the initiative to reach carbon neutrality for Centrale Nantes, a French "grande école".

Achieving carbon neutrality requires the establishment of an accurate carbon footprint [35], which has led HEIs to report on several efforts around the world during the last decade on this matter [36,37]. Moerschbaecher and Day [38] presented a study to estimate Louisiana State University's annual greenhouse gas (GHG) emissions from energy usage. Zhao and Zou [39] reported from Tsinghua University as a pioneer green university in China. Lambert and Cushing [40] described the impacts of an ecological footprint (EF) reduction strategy and the behaviour of students, faculty and staff at San José 
State University, California. Ortegon and Acosta [41] presented a benchmark for Colombian universities to assess the EF in order to facilitate the process at HEIs that are starting sustainability initiatives. Genta et al. [42] reported strategies followed at Politecnico di Torino University towards a green campus project and estimated the avoided EF. Orenstein et al. [43] reported a case study of how ecological considerations are integrated at Israel Institute of Technology, Israel, to develop objectives and guidelines for the campus strategic and spatial plans. Sima et al. [44] identified greening initiatives in a group of Romanian universities and evaluated perceptions of students/teachers/management staff. Jarillo et al. [45] reported the carbon footprint for online engineering education at the International University of La Rioja, Spain. Mendoza-Flores et al. [46] reported the case for the Cuajimalpa campus of the Autonomous Metropolitan University, where the carbon footprint was calculated using the GHG Protocol. Clabeaux et al. [47] evaluated the carbon footprint of Clemson University's campus using life cycle-based assessment methodology, providing a baseline for future mitigation. Varón-Hoyos et al. [48] reported the use of the GHG Protocol to calculate the carbon footprint at the Technological University of Pereira, Colombia, for the year 2018. In the local context, Aristizábal-Alzate and González-Manosalva [49] used the NTC-ISO 14064 standard to calculate the GHG emissions and the carbon footprint for the Robledo campus of the Instituto Tecnológico Metropolitano ITM located in Medellín.

In the case of Latin America, Bataille et al. [50] presented the objectives, approach and results of the Latin American Deep Decarbonisation Pathways project, which addresses strategies from different countries to reach net-zero GHG emissions while generating several benefits. Within this project, in the case of Colombia, Delgado et al. [51] presented a report addressing the mid-century deep decarbonisation strategy for the country, aligned with the socioeconomic context. In this scenario, universities can play a key role in regional and global agendas with their contribution through the incorporation of sustainability strategies [22].

This work addresses the strategy followed by two private Colombian universities as pioneers in carbon neutrality in the country: the Universidad Pontificia Bolivariana (UPB), a multi-campus university that became the first carbon-neutral university in Latin America in 2018, and Universidad Ean, a single-campus university that became the second carbon-neutral university in Colombia, as verified by the Colombian Institute of Technical Standards and Certification (ICONTEC) in 2021. Section 2 describes the methodology for achieving carbon neutrality within an institution, which includes quantifying the carbon footprint (GHG inventory), reduction, verification and compensation. Then Sections 3 and 4 contain the case studies for UPB as the first carbon-neutral university in Latin America and for Universidad Ean as the second university in Colombia to obtain the carbon-neutral certificate. Finally, conclusions are provided in Section 5.

Developing the GHG inventory towards the carbon neutrality within an institution.

\section{Methodology}

The process of developing the GHG inventory towards the carbon neutrality within an institution involves a series of steps that can be consolidated in three phases:

Phase I

- Definition of the scope of the carbon footprint: analysis of facilities and headquarters of the institution to define the scope of the carbon footprint calculation, identify emissions associated with different activities, classify them as direct or indirect emissions, and determine the scope and report of indirect emissions.

- Collection of direct and indirect data: data from activities are collected (energy, transportation, etc.) and emission factors defined. Data must be collected by taking into account the principles established by the GHG Protocol to achieve the highest possible accuracy in the calculation.

- Quantification of emissions: based on the collected information, compute the amount of GHG emitted into the atmosphere using data and emission factors, which are 
released by international organisations, government institutes, energy and/or environmental authorities, among others [52-62].

\section{Phase II}

- Analysis of results and conclusions: results from the calculation are analysed to determine their relevance within the institution's processes; the activities producing the greatest amount of emissions and the place where they are generated are identified in order to establish the respective actions. It is important to disclose these results inside and outside the institution.

- Mitigation actions: the identification of activities that are being developed, or that could be implemented and that clearly affect the emission of GHG, reducing them to the minimum possible in operational processes.

\section{Phase III}

- Verification: assessment of data and monitoring systems for projects and the institution to ensure that emissions and emission reductions are determined with accuracy, consistency, and transparency.

- Compensation strategies and carbon neutrality: once the carbon footprint has been quantified, strategies are established to reduce or offset the emissions generated by the institution.

\subsection{Carbon Footprint Measurement GHG Protocol-ISO 14064:2006}

The corporate carbon footprint can be determined using different methodologies, but the most used methodologies in the Colombian context are based on the GHG Protocol [63], and the NTC ISO 14064-1:2006 standard [64]. The GHG Protocol is the tool for calculating and communicating the inventory of GHG emissions, frequently used around the world for estimating the carbon footprint at the corporate level; it was the first initiative aimed at accounting for GHG emissions developed by the World Resources Institute (WRI) and the World Business Council for Sustainable Development (WBCSD). The ISO 14064-1:2006 standard determines specifications and guidelines for quantification, statement of emissions and removal of GHGs from a business or governmental or nongovernmental organisation and institution; it also includes the requirements for the design, development, management and GHG inventory verification.

\subsubsection{Principles}

The GHG accounting principles have been established by the ISO 14064-1:2006 standard. They are intended to guide GHG accounting and reporting to guarantee that the reported information is faithful, valid, and fairly accounts for an institution's GHG emissions [63]. These principles can be found in [63,64], and are listed as follows. "(i) Relevance: Ensure the GHG inventory appropriately reflects the GHG emissions of the company and serves the decision-making needs of users. (ii) Completeness: account for and report on all GHG emission sources and activities within the chosen inventory boundary. Disclose and justify any specific exclusions. (iii) Consistency: use consistent methodologies to allow for meaningful comparisons of emissions over time. Transparently document any changes to the data, inventory boundary, methods, or any other relevant factors in the time series. (iv) Transparency: transparency relates to the degree to which information on the processes, procedures, assumptions, and limitations of the GHG inventory are disclosed in a clear, factual, neutral, and understandable manner based on clear documentation and archives (i.e., an audit trail). Information needs to be recorded, compiled, and analyzed in a way that enables internal reviewers and external verifiers to attest to its credibility. (v) Accuracy: ensure that the quantification of GHG emissions is systematically neither over nor under actual emissions, as far as can be judged, and that uncertainties are reduced as far as practicable. Achieve sufficient accuracy to enable users to make decisions with reasonable assurance as to the integrity of the reported information." 


\subsubsection{Boundaries}

The GHG Protocol [63] establishes two distinct approaches to consolidate GHG emissions: the equity share and the control approaches. Hence, institutions must account for and report the GHG data according to such approaches. As it was established in the Protocol [63], after an institution has determined its organisational boundaries, operational boundaries shall be set; this means identifying emissions associated with its operations and classifying them as direct and indirect, while choosing the scope of accounting and reporting for such indirect emissions. Three scopes have been defined for GHG accounting and reporting purposes:

- Scope 1: Direct GHG emissions. Direct GHG emissions occur from sources that are owned or controlled by the institution [63], for instance, emissions from owned mobile sources or laboratory equipment.

- Scope 2: Electricity indirect GHG emissions. Accounts for GHG emissions from the generation of purchased electricity consumed by the institution [63], defined as the electricity that is purchased or otherwise brought into the organisational boundary of the institution. These emissions physically occur at the facility where electricity is generated.

- Scope 3: Other indirect GHG emissions, this is an optional reporting category that allows for addressing all other indirect emissions [63]. These emissions are a consequence of institutional activities, but occur from sources not owned or controlled by the organisation.

\subsubsection{Tracking}

Since institutions can perform structural changes, their emission profile is often altered, and therefore, historical emission data have to be recalculated [63]. Consequently, institutions must choose and report a base year, with appropriate reasons, for which verifiable emissions data are available. Then, the institutions shall develop a recalculation policy for base years, with an appropriate significance threshold that can be applied for deciding on historic emissions recalculation. This means that a qualitative and/or quantitative criterion needs to be used to define changes in data, inventory boundary, methods, or any other relevant factors. Finally, the verifier has to confirm the institution's adherence to its threshold policy. Cases that trigger recalculation of base year emissions are detailed in the GHG protocol [63].

\subsection{Mitigation}

The next step on the path to a carbon-neutral certification for HEIs involves identifying programmes and projects that allow for reduction in the generation of emissions in the aforementioned scopes. These programmes/projects include activities associated with physical infrastructure, research projects, and the actions developed by administrative units. For some organisations, the actions that allow the carbon footprint reduction may occur before the measurement, since they are planned within the framework of cost reduction and process efficiency, which are configured as opportunities to guarantee long-term execution; this allows an institution to reduce the associated impacts with the measurements.

\subsection{Verification and Carbon Neutrality}

The third-party verification corresponds to the evaluation of the GHG report, following reference procedures and requirements and the presented evidence related to the limits, sources, and quantification methodologies, among others. The general rule is that this initial verification of the carbon footprint, before choosing the base year, is performed by an entity that has demonstrated its competence and has established an internationally recognised evaluation methodology.

The carbon neutrality certification requires a commitment and the definition of a policy or a management plan for the carbon footprint from the organisation that has established such a goal. The carbon neutrality certification is a broader concept that 
involves a mix between achieving targeted actions to reduce GHG emissions or increase removals and offsetting residual emissions; choosing offsetting as a second option for the subject can achieve a net zero result in GHG emissions. The certification includes the measurement of the results obtained from the implementation of the policy or reduction plan and the implementation of corrective actions when the results are not as expected. It is also necessary to establish a policy for the selection and purchase of offsets before offsetting verified emissions, based on the quantification of the GHG inventory or the calculation of the carbon footprint; only for the base years, it is possible to compensate $100 \%$ of the absolute emissions. Therefore, a compensation policy with the characteristics of compensation needs to be defined, considering the type of project, geographical origin, quantification and reporting methodology, and double accounting. Emissions can be offset through carbon credits (Offsets, VERs, CERs or similar) that are certified under standards that comply with the principles of transparency, relevance, reliability, continuity, and accuracy. Finally, a document is prepared, containing the necessary information to show how carbon neutrality has been achieved, to request an audit by an independent and competent third party to verify that the declaration of carbon neutrality meets the requirements demanded by the external entity.

\section{Results Universidad Pontificia Bolivariana UPB}

\subsection{Organisational Context UPB}

The Universidad Pontificia Bolivariana (UPB) is a private non-profit Higher Education Institution founded in 1936, with legal status recognised through Resolution 48 of 1937-02-22 issued by the Ministry of Government of Colombia. The University is comprised of schools, faculties, centres, departments, institutes, and support units. The mission of the UPB is the comprehensive education of the people who are part of it, through the evangelisation of culture, the constant search for truth within teaching, research, and social projection processes, and the reassurance of values from Christian Humanism, for the good of society [65].

The University's Central Headquarters are located at Medellín's campus, with smaller campuses at Bucaramanga, Palmira, Montería and Bogotá; Figure 1 shows UPB's campuses locations and Table 1 shows main campuses within the country. In addition, the UPB is also present in other states: Norte de Santander, Caldas, Risaralda, Quindío, Cauca, Putumayo, Amazonas, Vaupés, Guainía, and Vichada, with undergraduate, postgraduate, ethnoeducation, and extension programmes, thanks to the agreements with other institutions. By 2020 the UPB reported 31,958 students and 3077 employees; Multicampus, see Table 2.

Table 1. UPB's main campuses within the country.

\begin{tabular}{|c|c|c|c|}
\hline Location & Photo & Location & Photo \\
\hline Medellín & & Bucaramanga & \\
\hline Circ. 1 70-01 & & km 7 vía Pied. & \\
\hline Area $686,664 \mathrm{~m}^{2}$ & & Area $143,225 \mathrm{~m}^{2}$ & \\
\hline $\begin{array}{c}\text { Buildings base } \\
\text { area } 200,420 \mathrm{~m}^{2}\end{array}$ & & $\begin{array}{l}\text { Buildings base } \\
\text { area } 44,992 \mathrm{~m}^{2}\end{array}$ & \\
\hline Montería & & Palmira & \\
\hline Cra. 6 97A-99 & & Cl. 44 SN 120 & \\
\hline Area $374,930 \mathrm{~m}^{2}$ & & Area $96,790 \mathrm{~m}^{2}$ & \\
\hline Buildings base & & Buildings base & \\
\hline area $18,001 \mathrm{~m}^{2}$ & & area $371 \mathrm{~m}^{2}$ & \\
\hline
\end{tabular}




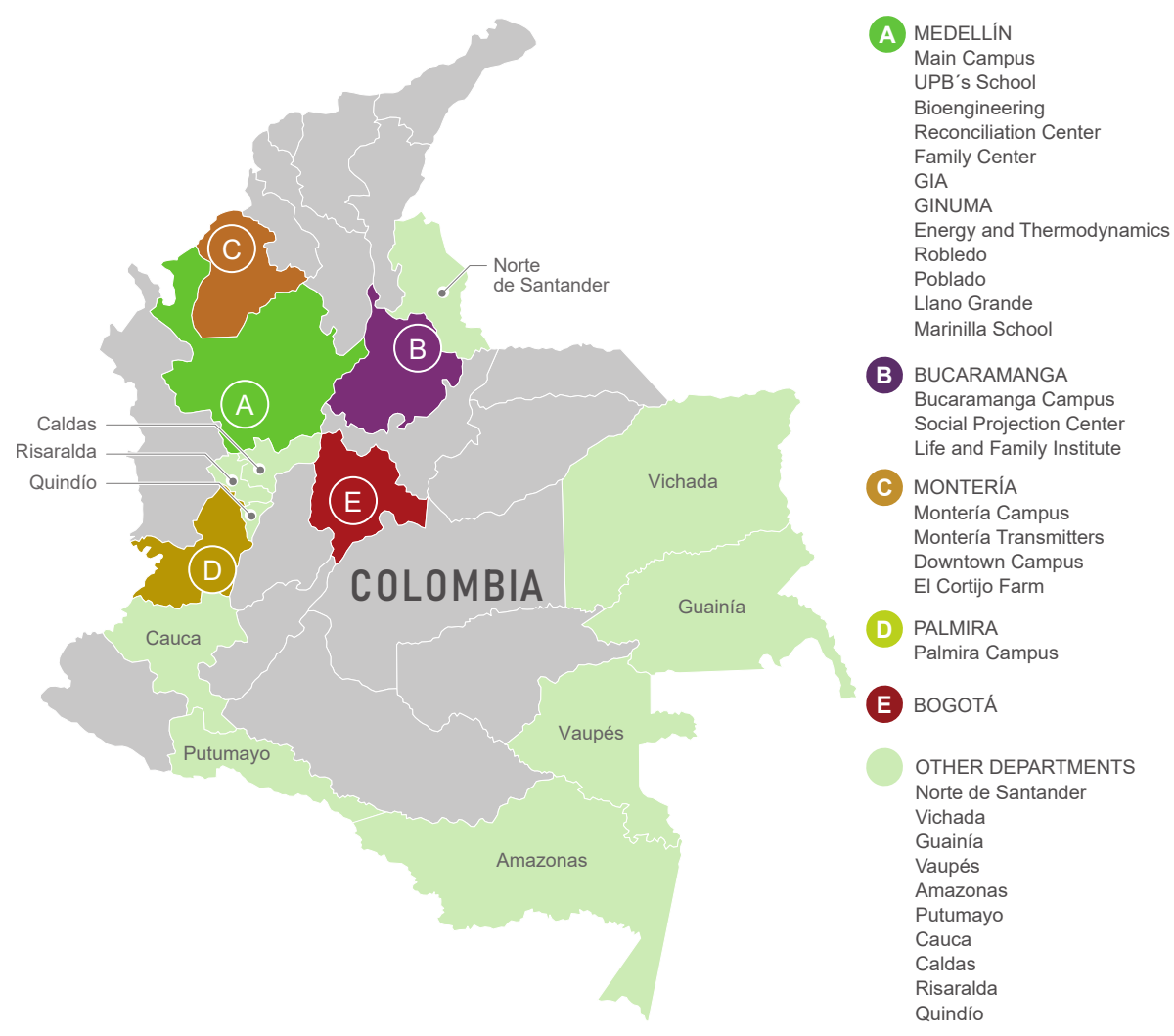

Figure 1. UPB's campuses locations and departments where programs are offered in Colombia.

Table 2. Total UPB's population by 2020 .

\begin{tabular}{cccccc}
\hline Indicator & Medellín & Bucaramanga & Montería & Palmira & Total \\
\hline Undergrad. Students & 11,440 & 3928 & 2809 & 841 & 19,018 \\
Postgraduate Students & 2572 & 825 & 418 & 119 & 4114 \\
Highschool Students & 4050 & - & - & - & 4050 \\
University Professors & 2135 & 411 & 361 & 131 & 3038 \\
Highschool Teachers & 244 & - & - & - & 244 \\
Admin. employees & 874 & 258 & 218 & 144 & 1494 \\
Total & 21,495 & 5422 & 3806 & 1235 & 31,958 \\
\hline
\end{tabular}

\subsection{Carbon Footprint Measurement UPB}

As detailed in the methodology section, the measurement of the carbon footprint at UPB was based on the GHG Protocol, with adaptations to the organisational context. In this sense, the operational and organisational limits, the base year, and the measurement scopes were defined in order to collect the necessary information to make the calculations and present the results to the stakeholders, aiming to achieve carbon-neutral status while guaranteeing the mitigation of the impacts generated in the development of institutional activities.

For the definition of the operational limits, UPB started the measurement process in 2017 at the headquarters (Medellín) at the time the sustainability office/program was created; this served as the starting point for expanding these limits to the Multicampus level for 2018 and subsequent years. The approach used for the carbon footprint report was based on operational control, since UPB accounts for $100 \%$ of the GHG emissions of its facilities. Therefore, a significance threshold of $10 \%$ was defined in the change in emissions from the base year.

The organisational limits were defined, taking into account the academic activities that represent relevant emissions and that can be prevented, mitigated, or controlled by the management of the UPB. In this sense, Scope 1 was defined by: (i) mobile sources owned by the University; (ii) stationary sources, represented mainly by power plants and laboratory 
equipment; (iii) fugitive emissions due to the use of air conditioners in different spaces of the headquarters and other campuses, including the R22 refrigerant, which is in the Montreal Protocol; (iv) physical or chemical processes associated with compost production. For Scope 2, the emissions from energy consumption were calculated by using official emission factors. For Scope 3, acquired goods and services, waste generation, business trips, and leased assets were taken into account. Table 3 contains the GHG emissions inventory for the UPB.

Table 3. UPB's GHG emissions inventory 2019-2020.

\begin{tabular}{|c|c|c|c|c|}
\hline Scope & GHG Category & Emission Factors & Value $\mathrm{tCO}_{2} \mathrm{e}$ & Scope $\mathrm{tCO}_{2} \mathrm{e}$ \\
\hline \multirow{28}{*}{1} & Mobile combustion: gasoline & IPCC [52] & 44.21 & \multirow{28}{*}{556.33} \\
\hline & & UPME [56] & & \\
\hline & Mobile combustion: diesel & IPCC [52] & 16.48 & \\
\hline & & UPME [56] & & \\
\hline & Mobile combustion: lubricants & IPCC [52] & 0.84 & \\
\hline & Mobile combustion: ethanol & IPCC [52] & 0.50 & \\
\hline & Mobile combustion: biodiesel & IPCC [52] & 0.03 & \\
\hline & \multirow[t]{2}{*}{ Stationary combustion: diesel } & IPCC [52] & 19.46 & \\
\hline & & UPME [56] & \multirow{3}{*}{61.12} & \\
\hline & \multirow[t]{2}{*}{ Stationary combustion: natural gas } & IPCC [52] & & \\
\hline & & UPME [56] & & \\
\hline & Stationary combustion: nitrous oxide & IPCC [53] & 39.75 & \\
\hline & Stationary combustion: acetylene & Thomas [66] & 1.50 & \\
\hline & \multirow[t]{2}{*}{ Stationary combustion: propane } & IPCC [52] & \multirow[t]{2}{*}{2.65} & \\
\hline & & UPME [56] & & \\
\hline & Stationary combustion: lubricants & IPCC [52] & 0.01 & \\
\hline & Stationary combustion: biodiesel & IPCC [52] & 0.01 & \\
\hline & $\mathrm{HFC} \mathrm{A} / \mathrm{C}$ and refrigeration: $\mathrm{CO}_{2}$ & IPCC [53] & 0.24 & \\
\hline & HFC A/C and refrigeration: $\mathrm{R}-123$ & IPCC [53] & 22.24 & \\
\hline & HFC A/C and refrigeration: $\mathrm{R}-22$ & IPCC [53] & 69.64 & \\
\hline & HFC A/C and refrigeration: $\mathrm{R}-410 \mathrm{a}$ & IPCC [53] & 250.68 & \\
\hline & HFC A/C and refrigeration: $\mathrm{R}-134 \mathrm{a}$ & IPCC [53] & 18.94 & \\
\hline & HFC A/C and refrigeration: $\mathrm{R}-507$ & IPCC [53] & 0.01 & \\
\hline & HFC A/C and refrigeration: $\mathrm{R}-508 \mathrm{~B}$ & IPCC [53] & 0.01 & \\
\hline & HFC A/C and refrigeration: R-404A & IPCC [53] & 2.88 & \\
\hline & Fugitive emissions & WFLDB [59] & 1.47 & \\
\hline & Composting production & U.S. EPA [55] & 3.67 & \\
\hline & Wastewater treatment plant & U.S. EPA [54] & 0.00 & \\
\hline 2 & Purchased electricity & UPME [60] & 2270.42 & 2270.42 \\
\hline \multirow{7}{*}{3} & Purchased goods: paper & EPNPC [61] & 78.78 & \multirow{6}{*}{1634.30} \\
\hline & Purchased services: transportation & AMVA [57] & 385.61 & \\
\hline & Leased assets (electricity) & UPME [60] & 103.4 & \\
\hline & Business travel: plane & ICAO [62] & 661.94 & \\
\hline & Business travel: taxis, car and bus & AMVA [57] & 219.96 & \\
\hline & \multirow[t]{2}{*}{ Waste generated in operations } & UK DBEIS [58] & 184.61 & \\
\hline & & & Total & 4461.06 \\
\hline
\end{tabular}

Emissions not contemplated in the Kyoto protocol were reported independently and were not included in the annual report. The following emissions of substances controlled by the Montreal protocol were identified: (a) leakage of R-12 and R-600 refrigerant gases used in air conditioning and refrigeration equipment located at the organisation's facilities, and (b) $\mathrm{CO}_{2}$ emissions from the use of biofuels, since in Colombia there is a $10 \%$ mix of bioethanol or biodiesel.

One of the most relevant aspects in measuring the carbon footprint for the UPB was the definition of the base year, taking into account the organisational and context dynamics. First, the measurement carried out by the UPB in 2017 contemplated an operational scope at 
the headquarters located in the city of Medellín, and the results were verified by ICONTEC. Then, because of the inclusion of campuses located at other cities, the base year was redefined in order to compare the emissions calculated year by year, based on reduction activities and mitigation of the generated impacts; see UPB's GHG emissions history from 2017 to 2020 in Table 4.

Table 4. UPB's historical GHG emissions 2017-2020.

\begin{tabular}{lcccc}
\hline Emissions & $\mathbf{2 0 1 7}$ & $\mathbf{2 0 1 8}$ & $\mathbf{2 0 1 9}$ & $\mathbf{2 0 2 0}$ \\
\hline $\mathrm{tCO}_{2} \mathrm{e}$ & 1211.4 & 2038.1 & 3193.4 & 1267.6 \\
\hline
\end{tabular}

The UPB selected 2018 as the base year since it had representative, reliable, and verifiable information about emission sources compared to previous years. This included: the Central Headquarters at Medellín including the school (pre, elementary, middle and high), the Poblado, Robledo, Marinilla, Llano Grande and Bogotá branches; and the Bucaramanga, Montería and Palmira campuses. Nowadays, the Medellín, Bucaramanga, Montería and Palmira campuses already have the verification and carbon neutrality certificate for the aforementioned base year, and the other small branches (Bogotá, Poblado, Robledo, Marinilla and Llano Grande) were included in the verification of the years 2019 and 2020 without modifying the organisational base year, since these emissions do not exceed the significance threshold that was defined at $10 \%$. Figure 2 shows an overview of the Multicampus UPB carbon footprint for 2020 that allows for the identification of the emissions distribution.

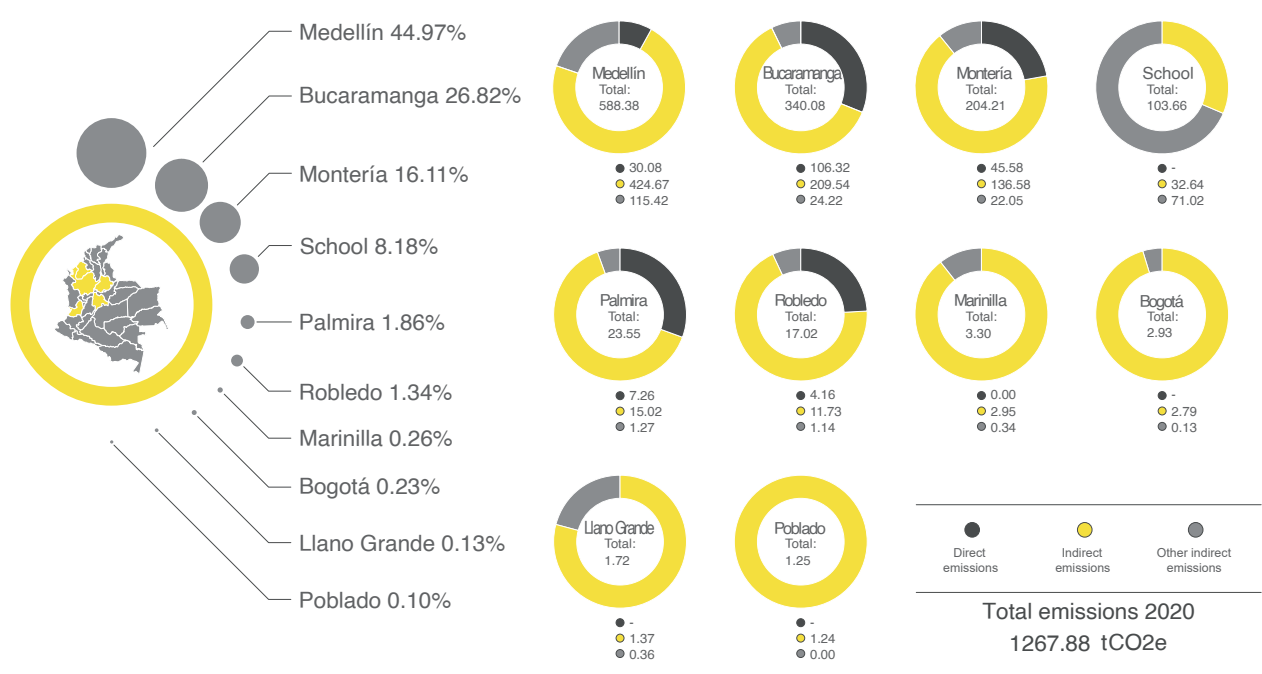

Figure 2. Multicampus UPB carbon footprint overview for 2020.

Finally, the measurement was verified by ICONTEC, which validates the source of information, provided data and calculations, and grants a certificate called "Greenhouse Gas Inventory Verification Statement", see Figure 3. 


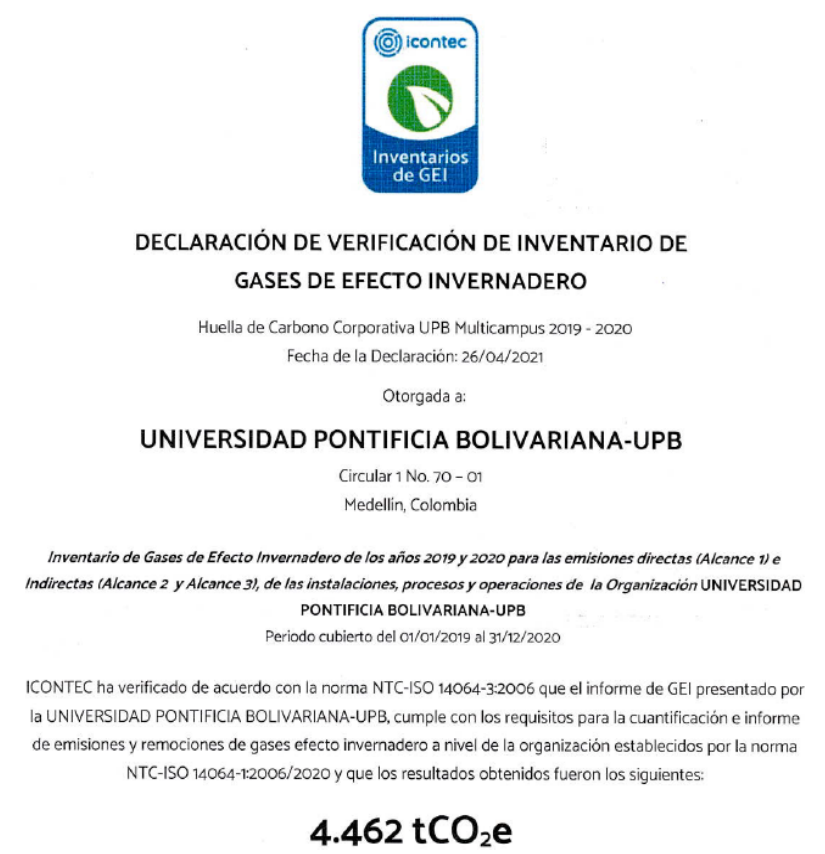

Figure 3. Multicampus UPB carbon footprint verification certificate 2019-2020.

\subsection{Reduction $U P B$}

The next step on the path to carbon-neutral certification for an organisation such as the UPB involves identifying programmes and projects that help to reduce the generation of emissions, considering the aforementioned scopes that include activities associated with physical infrastructure, research projects and actions performed by administrative units. The UPB's reduction projects contribute to the reduction of emissions, and the highest proportion has been oriented towards the carbon footprint. Furthermore, the execution of such projects has been guaranteed by the administration while considering four main issues: sustainable infrastructure, energy management, water management, and waste management.

\subsubsection{Sustainable Infrastructure}

Regarding sustainable infrastructure, UPB's actions have been aimed at improving the physical infrastructure with sustainable growth strategies in order to contribute to the strengthening of the university's model, including the construction of new buildings and re-powering of old ones, investments in adaptations of the buildings and public space, investment in office furniture and adaptation of classrooms, and renovation and acquisition of technological tools.

The UPB invested around USD $\$ 4.5$ million at the Montería campus to construct Building 3, a five-story building that meets the requirements in terms of energy efficiency, renewable energy, efficient use of water resources and reuse of rainwater. For this reason, since its construction, this building was projected to comply with environmental specifications in order to obtain the LEED Silver certification (Leadership in Energy and Environmental Design). In addition, the building has administrative offices, 16 classrooms for 35 students each, a spare-time room for 70 students, six meeting rooms for students, two meeting rooms and three professor production spaces, offices for professors with a capacity for 98 people, a cafeteria for 78 people, and other areas such as terraces furnished with modern and comfortable furniture.

The Bucaramanga campus started implementing an alternative energy production system using solar panels in 2019, which have been installed at strategically located points on campus to capture as much sunlight radiation as possible. Furthermore, based on the university's interest to strengthen the sustainability plan, the project of photovoltaic solar 
panels was implemented on the roof of Building L, providing 30\% of the total required energy for the building's operation.

At the main campus in Medellín, the UPB invested about USD $\$ 40$ million in the new Building 11 complex. This $28,000-\mathrm{m}^{2}$ complex consists of 57 classrooms, 67 high-quality laboratories, administrative offices and a large modular $1756-\mathrm{m}^{2}$ auditorium, called the Forum, with a capacity for 800 people, which can be divided into three smaller auditoriums. Additionally, the event centre is equipped with the latest high-format-event technology, which contributes to the realisation of sustainable events for the city and the country.

\subsubsection{Energy Management}

Aware of its role as a pioneer of energy sustainability within the country, the UPB has faced the challenge of implementing, operating and optimising the first smart grid of its kind in Colombia during the last seven years. This smart grid allows for the progressive integration of 10 centrally-manageable subsystems for the rational and efficient use of energy resources, mobility, construction, and the consolidation of the UPB main campus, denominated EcoCampus, as a smart-city and industry 4.0 living laboratory for the region and the country. Figure 4 shows UPB's energy consumption, including the average consumption per student and the evolution of energy consumption at each campus from 2017 to 2020 .

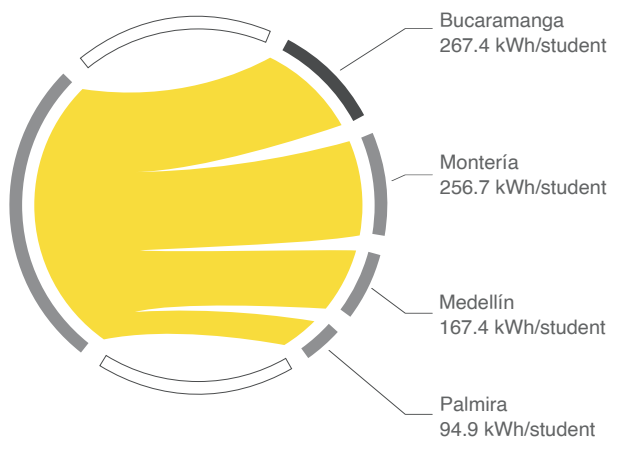

(a)

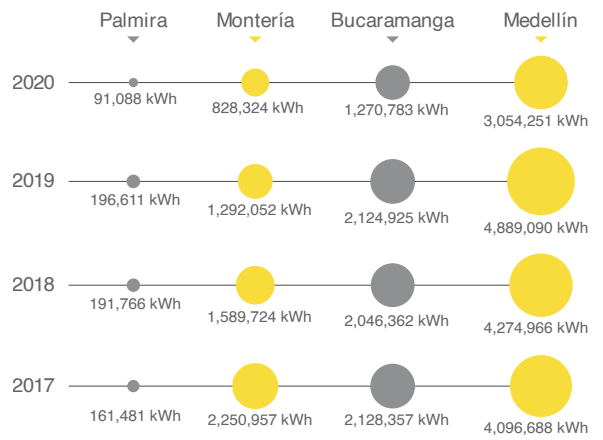

(b)

Figure 4. UPB's energy consumption. (a) Average consumption per student. (b) Energy consumption evolution at each campus from 2017 to 2020.

In order to balance the energy consumption increase due to the development of new infrastructure, during 2019 a new 53-kWp photovoltaic plant was incorporated into the EcoCampus electrical system, increasing the solar-installed capacity from $87 \mathrm{kWp}$ to $140 \mathrm{kWp}$. The total energy injection of the six operating solar generators reached $165,000 \mathrm{kWh}$ during 2019 , which represents an average of $4 \%$ of the consumed energy. There were days with a renewable-energy contribution of up to $25 \%$, for short periods, and up to a $12 \%$ average over the $24 \mathrm{~h}$ period, see Figure 5.

A meteorological and environmental-variable monitoring platform was deployed within the efforts for institutional growth and Multicampus strengthening. This new system has a total of nine state-of-the-art energetically-autonomous (with photovoltaic modules) meteorological stations, equipped with sensors for measuring wind speed, solar radiation, humidity, precipitation, PM2.5 , PM10, temperature and pressure; three have been installed in Medellín (EcoCampus), three in Bucaramanga, and three in Palmira. 


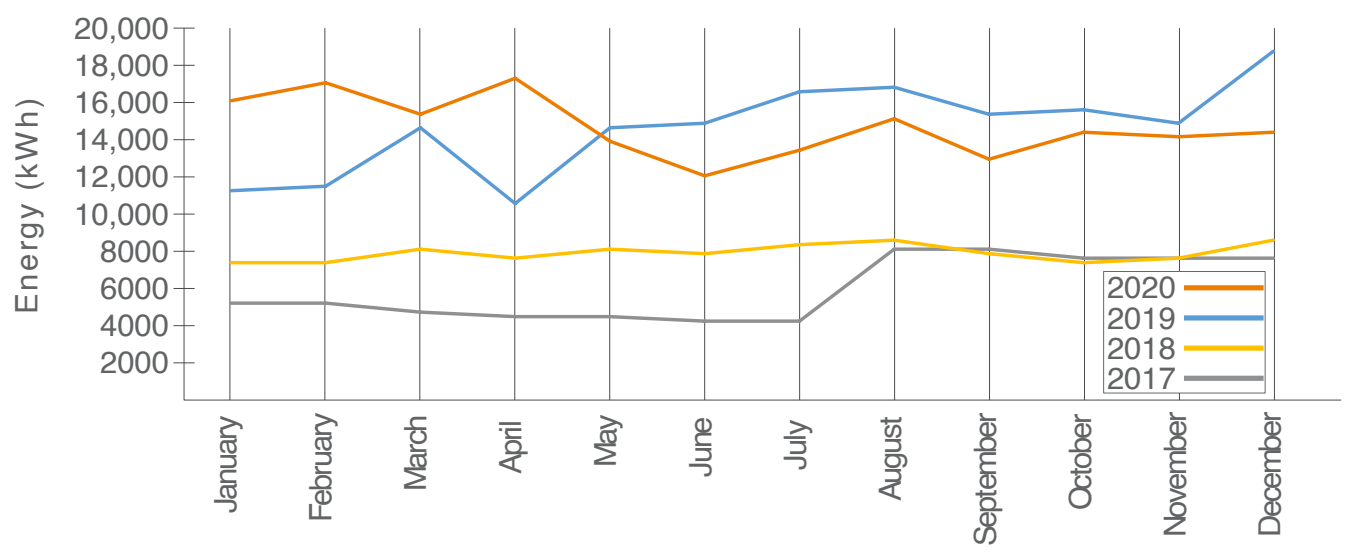

Figure 5. UPB's energy solar generation evolution and reduction of power consumption.

\subsubsection{Water Management}

The UPB has consolidated the baseline for the use and exploitation of water resources to develop its activities, allowing for the definition of a roadmap for reduction and efficient use efforts. In addition, the traceability of data was strengthened, and a management model was designed around the resource, which permits the identified actions to reduce the impacts associated with the consumption and discharge of water.

The university has defined environmental and sustainability policies that have allowed for the consolidation of the culture of sustainability through programmes and projects that aim to reduce and mitigate environmental impacts. UPB has been calculating the campus water footprint, and in 2020 it started the accreditation process for the used methodology with the support of ICONTEC. Figure 6 shows UPB's water consumption and water footprint. Additionally, the university has been monitoring the monthly consumption of the campuses' meter systems in order to verify possible losses or leaks of water.

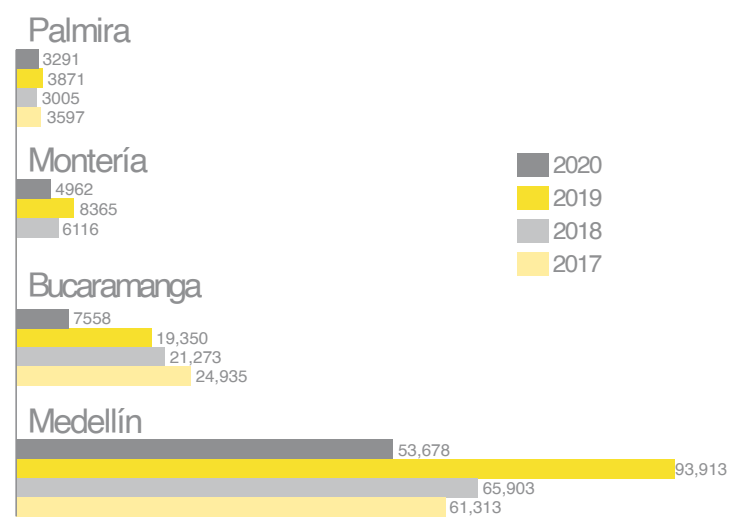

(a)

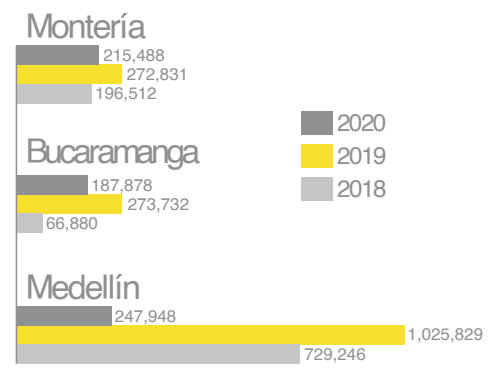

(b)

Figure 6. UPB's water consumption and footprint. (a) Water consumption in $\mathrm{m}^{3}$ for 2017-2020. (b) Water footprint in $\mathrm{m}^{3}$ for 2018-2020. Water consumption at Medellín was unusual during 2019 due to the construction of the the new Building 11 complex. Consumption and footprint are unusual for 2020 due to the COVID-19 pandemic.

Finally, and as a contingency plan for the COVID-19 pandemic, additional handwashing sinks were installed on campus near existing water supply networks and drains to follow safety bio protocols, putting the health of the community as a priority.

\subsubsection{Waste Management}

Among all the environmental issues, the reduction or elimination of waste has become a priority for UPB. Currently, the university is carrying out an operational management plan that first considers a review of information related to the use and final disposal of 
the generated waste. Then, a tool that can register data and monitor waste in terms of quantities and classification permits then evaluates the possible alternatives for efficient management. This has improved the UPB's Multicampus actions and guidelines on waste management and has provided advantages and benefits. Since 2015, the main campus in Medellín has a composting station that uses plant and tree waste to produce a natural fertiliser for trees and gardens, reducing the impacts caused by transportation and disposal to a landfill, and consequently reducing the carbon footprint. Additionally, vermicompost and compost processes are carried out at the Bucaramanga campus since its foundation. One of the main strategies for waste management is the efficient use of resources that favor the minimization of waste generation. Aligned with this, in 2017, the University started a zero-paper campaign, optimising the use of paper in available technologies.

The UPB still has great challenges related to data quality in waste management in the collection and systematisation of information related to hazardous and non-hazardous waste at all campuses nationwide. Therefore, the University is seeking to run a wellfounded standardised data collection system. Figure 7 shows UPB's Multicampus waste generation for 2020 .

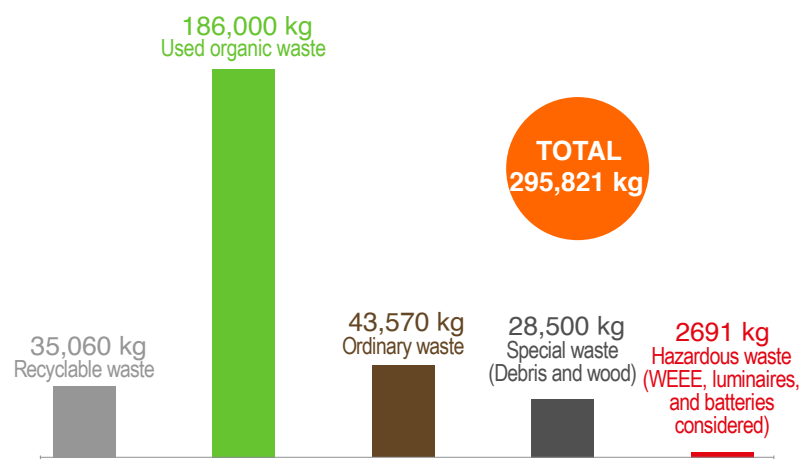

Figure 7. UPB Multicampus waste generation for 2020.

\subsection{Compensation UPB}

The UPB has a sustainability policy that defines the consolidation of the culture of sustainability through programmes and projects that aim to reduce and mitigate the environmental impacts generated on campus and that affect stakeholders. Among these programmes / projects, those that directly contribute to the reduction of GHG emissions and those focused on training and increasing the awareness of stakeholders are highlighted; they will generate short and medium-term impacts, helping to consolidate the sustainability culture of the university.

The main purpose of the neutrality programme is to identify and propose the programmes that will allow for the reduction of GHG emissions and that will build a culture of sustainability of the UPB: (i) information transparency management, (ii) communication for sustainability, (iii) generation and strengthening of capacities, (iv) monitoring of crucial sustainability variables, and (v) strategic articulation of sustainability. Table 5 contains the programmes and projects defined by the sustainability programme at the UPB and that support the roadmap for carbon neutrality in the long term.

For 2019 and 2020, the UPB acquired carbon credits in projects for the reforestation of soils that had been degraded by livestock and agriculture activities in the Department of Antioquia, which implies diversification of land use. Additionally, it seeks to reduce the pressure of the forest and remove GHG while increasing tree coverage in the region and boosting employment.

Certification of carbon neutrality requires a commitment and the definition of a policy or a management plan for the carbon footprint from institutions seeking to become carbon neutral organisations. This certification involves a mix between the implementation of actions to reduce GHG emissions and the compensation of residual emissions, the latter being the second option for the organisation that wants to achieve a net zero result of GHG 
emissions. The certification of carbon neutrality includes assessing the results obtained from the implementation of the policy and the implementation of corrective actions when the results do not meet what has been proposed. Figure 8 shows the Multicampus UPB carbon neutrality certificate for the years 2018-2021.

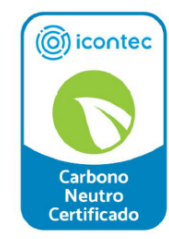

CERTIFICADO DE CARBONO NEUTRO

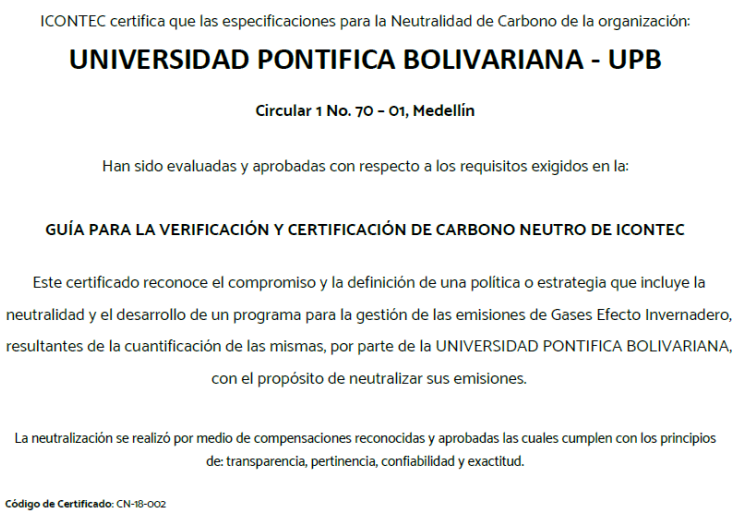

Figure 8. Multicampus UPB carbon neutrality certificate 2018-2021.

Table 5. UPB's sustainability programs/projects.

\begin{tabular}{|c|c|c|}
\hline Program & Project & Purpose \\
\hline Information & 1. Information & $\begin{array}{l}\text { Develop a platform that integrates information from all campuses in order to monitor and } \\
\text { control the carbon footprint indicators }\end{array}$ \\
\hline Communication & 2. Communication & $\begin{array}{l}\text { Define and implement an academic and scientific dissemination agenda for the visibility and } \\
\text { construction of the culture of sustainability regarding the measurement of the carbon footprint }\end{array}$ \\
\hline Capacities & $\begin{array}{l}\text { 3. Courses } \\
\text { 4. Services } \\
\text { 5. Training }\end{array}$ & $\begin{array}{l}\text { Design and present a course for all undergraduate and postgraduate programs, fostering the } \\
\text { consolidation of the sustainability culture regarding the measurement of the carbon footprint } \\
\text { Design an academic offer: courses, diplomas, seminars, forums, oriented to different } \\
\text { dimensions of sustainability, from internal capacities to enhance the University extension offer } \\
\text { Qualification for professors and staff on sustainability to contribute to the generation of a } \\
\text { critical mass needed for decision-making processes towards climate change }\end{array}$ \\
\hline \multirow{6}{*}{ Monitoring } & 6. Purchasing & $\begin{array}{l}\text { Classify goods and services acquired by the University in order to incorporate environmental, } \\
\text { economic, and social criteria in their acquisition, taking into account the impacts generated } \\
\text { throughout their life cycle, from extraction to its final disposition } \\
\text { Assess main externalities and establish improvement actions to contribute to the development }\end{array}$ \\
\hline & $\begin{array}{l}\text { 7. Externalities } \\
\text { 8. Footprints }\end{array}$ & $\begin{array}{l}\text { of the UPB, while reducing impacts and enhancing benefits of University's operations } \\
\text { Measure environmental footprints at the multicampus level to review and validate historical } \\
\text { results and propose mitigation actions }\end{array}$ \\
\hline & 9. Waste & $\begin{array}{l}\text { Formulate and implement a comprehensive plan for hazardous waste and chemical substances } \\
\text { management, standardizing waste management to meet current environmental regulations }\end{array}$ \\
\hline & 10. Energy & $\begin{array}{l}\text { Audit energy consumption of equipment and supplies to design and implement an energy } \\
\text { efficiency plan, which allows the reduction of emissions of Scope } 2 \text { of the carbon footprint }\end{array}$ \\
\hline & 11. Water & $\begin{array}{c}\text { Monitor water consumption and discharge, to design and implement the management/saving } \\
\text { plan of efficient water use }\end{array}$ \\
\hline & 12. Mobility & Reduce GHG emissions associated with displacements of students and employees \\
\hline Articulation & 13. Strategies & $\begin{array}{l}\text { Design an integration mechanism for the UPB's main strategies: planning, strategic focuses, } \\
\text { vice presidencies, university strategy, human resources, among others, towards the } \\
\text { sustainability strategy and commitments to reduce GHG emissions }\end{array}$ \\
\hline
\end{tabular}

\section{Results Universidad Ean}

\subsection{Organisational Context Universidad Ean}

Universidad Ean is a private non-profit higher education institution founded in 1963 as a business school and recognised as Universidad Ean in 2006, with legal status recognised 
through Resolution 2898/1969 issued by the Ministry of Justice. Faculties, departments, and institutes constitute the university. The mission of Universidad Ean is to contribute to the comprehensive training of people (i.e., knowledge, skills, and capabilities) and stimulate their entrepreneurial aptitude in such a way that their action contributes to the economic and social development of people. Its higher proposal is to contribute to such type of training and sustainable entrepreneurship, by considering research, leadership, and innovation as fundamental elements in the generation of abundance for humanity.

The University has a four-location campus in Bogotá, Colombia: Founders campus, Ean Legacy campus, Laboratories and Chile Street campus, Table 6. Universidad Ean is also present all over the country and within ten countries around the world with undergraduate and continuing education programs; the University has agreements with other institutions and offers postgraduate programs at departments of Bolivar, Atlántico, Sucre, Tolima, Huila, Cauca, and Meta. Currently, the organisation has 9804 students, Figure 9, and around 420 employees.

Table 6. Universidad Ean's campus locations in Bogotá.

\begin{tabular}{|c|c|c|c|}
\hline Location & Photo & Location & Photo \\
\hline $\begin{array}{c}\text { Founders } \\
\text { Calle } 7911-45 \\
\text { Area } 6606 \mathrm{~m}^{2} \\
\text { Built } 22,607 \mathrm{~m}^{2}\end{array}$ & & $\begin{array}{c}\text { Ean Legacy } \\
\text { Calle } 7811-47 \\
\text { Area } 22,607 \mathrm{~m}^{2} \\
\text { Built } 20,000 \mathrm{~m}^{2}\end{array}$ & \\
\hline $\begin{array}{l}\text { Basic science } \\
\text { Cl } 749-49 \\
\text { Area } 540 \mathrm{~m}^{2} \\
\text { Built } 642 \mathrm{~m}^{2}\end{array}$ & ᄅ & $\begin{array}{l}\text { Chile Street } \\
\text { Cl } 729-71 \\
\text { Area } 3064 \mathrm{~m}^{2} \\
\text { Built } 4801 \mathrm{~m}^{2}\end{array}$ & \\
\hline
\end{tabular}

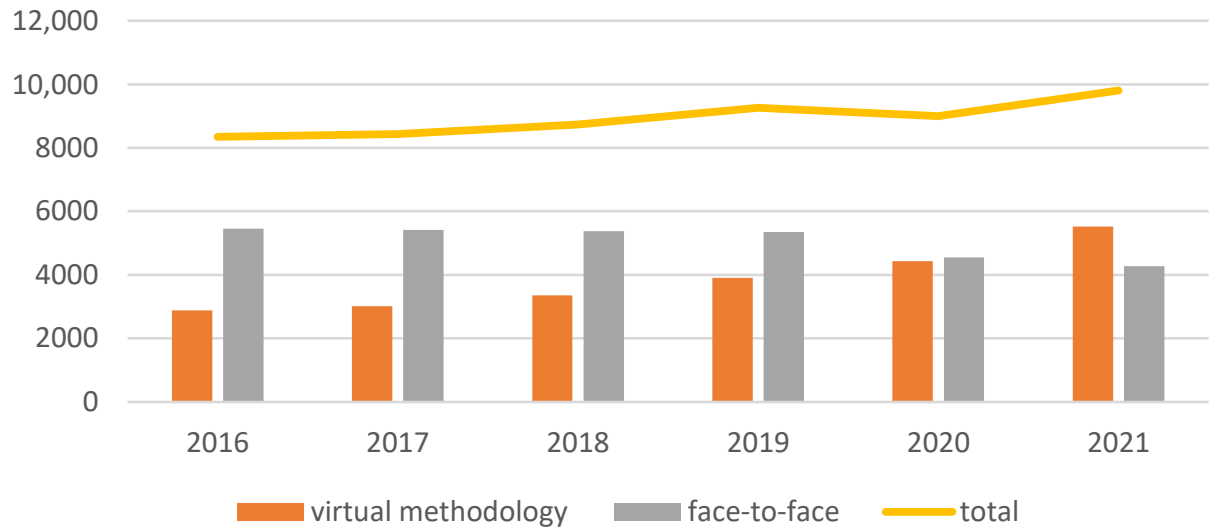

Figure 9. Universidad Ean students population. 


\subsection{Carbon Footprint Universidad Ean}

The carbon footprint measurement at Universidad Ean was based on the standard ISO 14064-1:2006 methodology, since its five strategic principles are aligned with the institution's principles: relevance, completeness, consistency, transparency, and precision. In this sense, the operational and organisational limits, the base year, and the measurement scopes were defined to collect the necessary information to obtain the emissions inventory, and later to work towards achieving the neutral carbon status.

The organisation's limits were focused on control: the university accounted for $100 \%$ of its GHG emissions attributable to operations at its facilities, over which it exercises control (operational or financial). However, the operational control criterion was emphasised within the development of the inventory. The year 2019 was selected as the limit for developing the GHG inventory, establishing the base year for the subsequent comparative studies. The construction activities of the Ean Legacy project were explicitly excluded, and a significance threshold of $5 \%$ was defined in the change in emissions from the base year.

Regarding the operating limits, for Scope 1 of the GHGP, the direct emissions in Universidad Ean were defined as: (i) refrigeration and air conditioning equipment, (ii) recharging fire extinguishing equipment, (iii) emissions from natural gas consumption in cafeterias, (iv) consumption of liquid fuels in mobile and fixed sources, and (v) laboratory gas consumption. Global warming potential factors and emission factors were used to compute and report the gas emissions inventory (R404a, R134a, R410A, R407C, HCFC-123, $\mathrm{CH}_{4}$ and $\mathrm{N}_{2} \mathrm{O}$ ). For Scope 2, the emissions from purchased energy consumption were calculated, using information provided by the national authority. Table 7 contains the GHG emissions inventory for Universidad EAN, which does not include the evaluation for Scope 3. Figure 10 shows the verification certificate from ICONTEC.

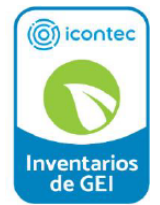

DECLARACIÓN DE VERIFICACIÓN DE INVENTARIO DE GASES DE EFECTO INVERNADERO

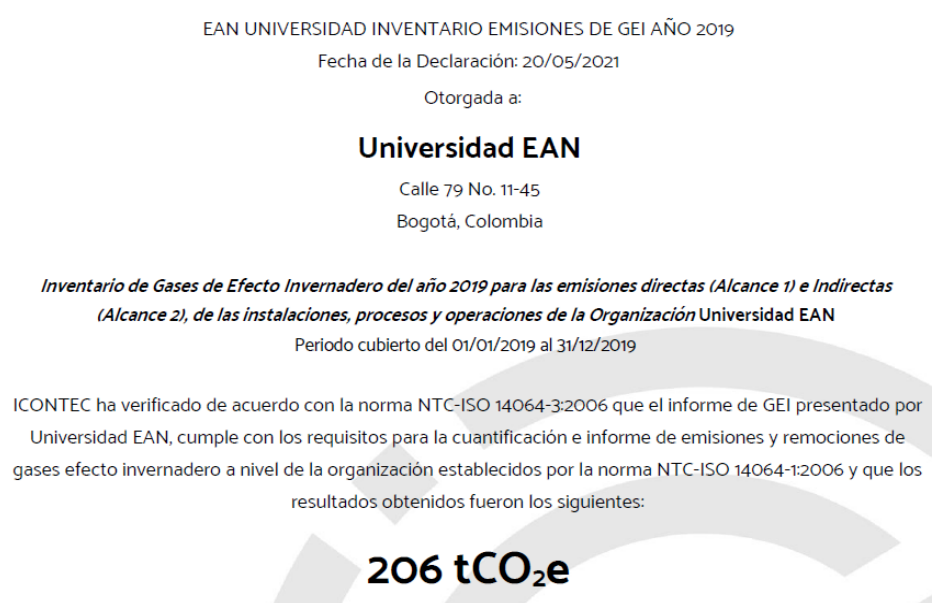

Figure 10. Universidad Ean carbon footprint verification certificate 2019. 
Table 7. Universidad EAN's GHG emission inventory 2019.

\begin{tabular}{|c|c|c|c|c|}
\hline Scope & GHG Category & Emission Factors & Value $\mathrm{tCO}_{2} \mathrm{e}$ & Scope $\mathrm{tCO}_{2} \mathrm{e}$ \\
\hline \multirow{7}{*}{1} & Refrigeration equipment & IPCC $[52,53]$ & 0.15 & \multirow{7}{*}{46.64} \\
\hline & $\mathrm{A} / \mathrm{C}$ equipment & IPCC $[52,53]$ & 9.99 & \\
\hline & Fire extinguishing equipment & IPCC [53] & 29.25 & \\
\hline & Natural gas in coffee shops & UPME [56] & 0.08 & \\
\hline & Liquid fuels in mobile/fixed sources & UPME [56] & 2.65 & \\
\hline & Laboratory gas consumption & $\operatorname{IPCC}[52,53]$ & 4.52 & \\
\hline & & UPME [56] & & \\
\hline 2 & $\begin{array}{l}\text { Consumption of externally produced } \\
\text { electrical energy }\end{array}$ & IPCC [52] & 158.98 & 158.98 \\
\hline \multirow[t]{2}{*}{3} & Not included & Not included & - & - \\
\hline & & & Total & 205.62 \\
\hline
\end{tabular}

\subsection{Reduction Universidad Ean}

Once the GHG emissions for the base year had been evaluated, and in order to carry out a process aimed at achieving carbon neutrality, it was proposed to reduce emissions at Universidad Ean through actions performed in order to reduce the consumption of fossil fuels and electricity. The following guidelines, for short-, medium- and long-term, were defined: (i) generation of renewable energy to reduce GHG emissions; (ii) replacement of the use of institutional fossil fuel-powered vehicles with electric vehicles; (iii) updating and reviewing the inventory of conventional lights and replacement with energy-efficient lighting systems; (iv) evaluation of the implementation and adjustment of control systems in the mechanical aeration equipment. (v) analysis of energy consumption compared to the fixed population (collaborators) and floating (students and stakeholders), who carry out activities at the university headquarters. (vi) design a training and awareness plan on good practices to reduce energy consumption for administrative and student personnel. Hence, the following short and medium-term objectives were proposed:

- Reduce GHG emissions related to electricity consumption from the grid, through the generation of renewable energy using solar panels at the Founders Building. In 2015, Universidad Ean installed solar panels to produce renewable energy in such building, which came into operation by June 2016. Although the project's useful life was set to 25 years, the carbon neutrality report considers approximately half of the useful life of the project, 12 years. In 2019, $7651 \mathrm{kWh}$ were generated, which is equivalent to $1270 \mathrm{kgCO}_{2}$ e mitigated.

- Reduce the GHG emissions generated by the fossil fuel consumption in vehicles by replacing them with electric ones. Furthermore, Universidad Ean hopes to increase their use as official transportation of directives to different events in the short term. Likewise, strategies related to the development of remote activities will be evaluated to contribute to the reduction of fossil fuel consumption.

- Reduce energy consumption by replacing inefficient energy lights with low energy consumption lighting systems and installing smart plugs in the Founders Building. One of the main objectives of Universidad Ean is to reduce electricity consumption, since it is the activity with the highest participation in the generation of emissions (around 77\% according to the GHG inventory). Since lighting plays a large role in energy consumption, the university is planning to replace low-efficiency lights with energy-efficient ones, since the new ones can reduce energy consumption by 50 to $85 \%$ as estimated in $[67,68]$. Additionally, Universidad Ean plans to install smart plugs that contribute to optimising the energy consumption of electronic equipment in the Founders Building.

- $\quad$ Reduce energy consumption by adjusting the control systems in the mechanical aeration equipment of the Ean Legacy and Founders buildings. The adjustment to the control system that is proposed to the mechanical aeration equipment is the increase 
(upper temperature) and reduction (lower temperature) of the comfort temperature set-point by $1{ }^{\circ} \mathrm{C}$. The comfort temperature of places where sedentary activities are carried out, e.g., offices and regular classrooms, has been set to $27^{\circ} \mathrm{C}$. Additionally, it is recommended that the air temperature in heated places should not exceed $21^{\circ} \mathrm{C}$, and in refrigerated places, it is recommended to be around $26^{\circ} \mathrm{C}$ [69].

In the medium and long term, the actions are framed in the progress of processes to improve the management of GHG emissions over time. Following this, Universidad Ean built the Ean Legacy building that came into operation in 2021, which led, together with the COVID-19 pandemic, to change the venues that operated under lease in 2019. For this reason, in the framework of this strategy, the university's operating conditions are being updated and their influence on GHG emissions needs to be monitored. Furthermore, this framework of action will make it possible to advance in the consolidation of the remaining objectives: (i) analyse energy consumption of the fixed population (collaborators) and the floating population (students) who carry out activities at the university headquarters, and (ii) reduce energy consumption by implementing a training and awareness plan for administrative staff and students. Hence, the goals set for these objectives are:

- Generate renewable energy through the photovoltaic panel system located in the Founders building for 2021 and 2022.

- Reduce vehicle fuel consumption by $30 \%$ in the first year (2021) and up to $70 \%$ in the second (2022).

- Replace $30 \%$ of the high-energy-consumption luminaires in the Founders building with low-energy-consumption luminaires by 2021 . The remaining $70 \%$ will be replaced in the second year (2022).

- Install smart plugs at the Founders Building in $10 \%$ of the connections within the first year (2021) and up to $30 \%$ within the second year (2022).

- Reduce the energy consumption of the mechanical ventilation systems of the Ean Legacy and Founders buildings by varying the temperature set-point by $1{ }^{\circ} \mathrm{C} \mathrm{com-}$ pared to the comfort temperature for the cooling and heating processes.

Actions related to reductions in electrical energy consumption may not reflect net reductions in GHG emissions, which are associated with the increase in staff and/or students over time. Therefore, these actions are approached from a standardised analysis of energy consumption based on the fixed population (collaborators) and floating population (students) in such a way that good practices are implemented.

\subsection{Compensation Universidad Ean}

Universidad Ean developed the Policy for Sustainability and Sustainable Entrepreneurship in 2020, as a complement to its higher purpose previously formulated in 2016. In this sense, climate change is one of the strategic issues that Universidad Ean has been synergistically promoting when taking actions towards sustainability and sustainable entrepreneurship at various institutional areas. Accordingly, Universidad Ean formulated its Carbon Neutrality Strategy 2021-2023 as a general guideline for the institution regarding its commitment to identifying and implementing actions to mitigate GHG emissions and offset residual emissions caused by its activities.

To advance in the achievement of carbon neutrality proposed by Universidad Ean, once the carbon footprint had been quantified, it was proposed to offset the GHG emissions through the acquisition of verified carbon credits from projects or initiatives whose focus was on the conservation of forests at the national level, which contribute to the protection of biodiversity and natural capital. In this way, the fight against climate change is supported by financing projects that reduce or avoid burning fossil fuels or emitting GHG into the atmosphere. In this way, for the year 2019 the Universidad Ean acquired carbon credits in the project for the conservation of the Galilea-Amé forest, an area rich in biodiversity that also has water sources from the Cabrera River and the Prado River, located to the west of Colombia. This project, with an extension of $13,727 \mathrm{Ha}$ within the $29,859 \mathrm{Ha}$ of total forest, 
is part of the priority areas for conservation in the Andes and Amazonian foothills, since it is located at the biological corridor that connects the Andean forest and Alto Andean with the páramos of the Sumapaz National Natural Park (one of the most extensive páramos in the world). In addition, it is the last remnant of primary forest in the department of Tolima, and contains the source of the Negro River, one of the tributaries of Hidroprado, a 4300-Ha reservoir that allows for the generation of $51 \mathrm{MW}$ of hydroelectricity to the interconnected national system.

With this carbon neutrality plan, the implementation of the proposed actions, and the acquisition of carbon credits to offset the evaluated and verified carbon footprint, Universidad Ean advanced towards the carbon neutrality certification process under ICONTEC standards. Figure 11 shows Universidad Ean's carbon neutrality certificate for the years 2021-2024.

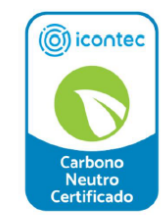

CERTIFICADO DE CARBONO NEUTRO

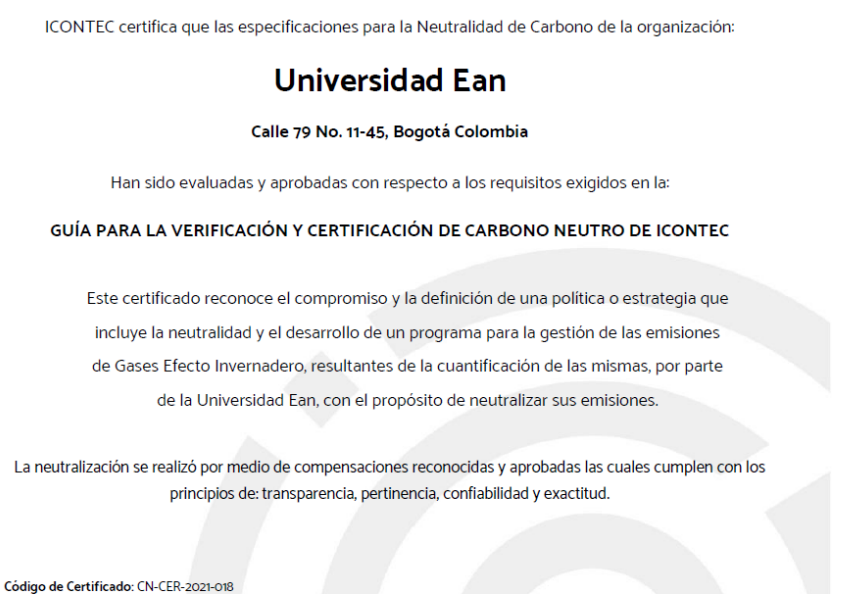

Figure 11. Universidad Ean carbon neutrality certificate 2021-2024.

\section{Conclusions}

This paper addressed the work that has been done towards achieving carbon neutrality by two private HEIs in Colombia. It has been shown how these institutions determined the carbon footprint based on the GHG Protocol by: defining the scope, collecting data and quantifying emissions; analyzing results and proposing mitigation actions; and undergoing verification processes and proposing compensation strategies. The case was presented for the Universidad Pontificia Bolivariana, a multi-campus university that created the sustainability office/programme in 2017 and became the first carbon-neutral university in Latin America by 2018, and Universidad Ean, a single-campus university that has become the second carbon-neutral university in Colombia.

A limitation of this paper is that only two case studies were included. However, it summarises how these HEIs, of different sizes and with different organisational operations, can follow the GHG protocol and country regulations in order to determine the carbon footprint, together with actions/projects that aim not only at reducing GHG emissions but also to building a culture of sustainability within the institution and with its stakeholders. Another issue encountered when achieving the carbon-neutrality certification using the proposed methodology, is that including the Scope 3 of the GHG protocol (other indirect emissions) is not mandatory, which allows some organisations (such as HEIs) to avoid including emissions that are often outsourced. In the case of the UPB we found that such 
emissions correspond to $37 \%$ of the total reported in the GHG inventory, which is highly representative.

The GHG Protocol, as developed by the World Resources Institute and established by the ISO 14064-1:2006 standard, has been extensively used as a methodology to account for GHG emissions within several institutions. However, it has been mainly used at the corporate level and not exactly at HEIs, which often exhibit different dynamics than businesses or industries whose GHG emissions mainly rely on Scopes 1 and 2. This explains why, for instance, Scope 3 should be mandatory for some institutions such as HEIs, since other indirect emissions are transfered to the external provider. This issues may lead to the development of a new framework that can account for indicators and evidences that consider HEIs particular dynamics.

Consequently, further works and projects at UPB and Universidad Ean after the carbonneutrality has been achieved, may be directed towards effectively reducing GHG emissions, which will lead to reduce compensation payments. Additionally, clear strategies are needed for these HEIs to expand their boundaries by including all the activities associated to the organisation that are carried out at their different locations.

The HEIs' commitment to tackle challenges derived from climate change has become a differentiating value that transcends the substantive missions of teaching, research, and transfer, and allows the HEI to demonstrate its commitment as one of the key actors in this problem. HEIs are not only providing knowledge for the solution of territorial problems, especially those associated with SDG 13, but they are also strengthening their academic and research programmes and turning campuses into city laboratories through the implementation of scalable prototypes for the productive sectors that generate great impacts. Therefore, the HEIs that manage to achieve carbon neutrality for their campuses can also strengthen joint and collaborative work, guarantee knowledge transfer, establish a tangible commitment for their stakeholders, and integrate environmental responsibility into the development of their missionary activities.

Carbon-neutral HEIs are now key players in the sustainability ecosystem, since they have acquired a commitment that transcends compliance with the Sustainable Development Goals, proposing a commitment to regenerative development with the establishment of clear and solid bases, which are built on rigorous academic and investigative exercises. Such good practices can be then transferred to different organisations and companies that generate environmental impacts, both through formal education (degrees) and professional training (certificates). These HEIs are encouraging the academic sphere to assume an active role, which until now has been limited to the training and strengthening of the capacities of the professionals of the future, towards global problems by participating in the design of roadmaps towards carbon neutrality. This can be done by promoting projects that reduce and mitigate GHG emissions, and by adapting measures through the projection of prospective and regenerative scenarios, in the context of economic development and social growth.

Author Contributions: Conceptualization, A.M.O., L.F.Ú., R.E.V., C.N.-L., M.E.R., J.A.M. and W.L.F.; methodology, A.M.O., L.F.Ú., M.E.R. and J.A.M.; validation, R.E.V., C.N.-L. and W.L.F.; investigation, A.M.O., L.F.Ú., R.E.V., C.N.-L., M.E.R., J.A.M. and W.L.F.; writing-original draft preparation, R.E.V., C.N.-L.; writing-review and editing, R.E.V., C.N.-L. and W.L.F.; supervision, A.M.O. and W.L.F. All authors have read and agreed to the published version of the manuscript.

Funding: This work was developed with the funding of Universidad Pontificia Bolivariana, UPB; and Universidad Ean.

Institutional Review Board Statement: Not applicable.

Informed Consent Statement: Not applicable.

Data Availability Statement: The data presented in this study are available on request from the corresponding author. The data are not publicly available due to the fact that the carbon footprint is computed at every organization and then verified by ICONTEC. 
Acknowledgments: Thanks to UPB's designer Laura Durango for her valuable contribution in the design and elaboration of the figures.

Conflicts of Interest: The authors declare no conflict of interest.

\begin{tabular}{|c|c|}
\hline \multicolumn{2}{|c|}{ Abbreviations } \\
\hline \multicolumn{2}{|c|}{ The following abbreviations are used in this manuscript: } \\
\hline AMVA & $\begin{array}{l}\text { Área Metropolitana del Valle de Aburrá } \\
\text { (Environmental authority for Medellín's metropolitan area) }\end{array}$ \\
\hline $\mathrm{EF}$ & Ecological Footprint \\
\hline EPA & U.S. Environmental Protection Agency \\
\hline EPNPC & Environmental Paper Network Paper Calculator v4.0 \\
\hline FECOC & $\begin{array}{l}\text { Factores de Emisión de los Combustibles Colombianos } \\
\text { (Colombian Fuels Emission Factors) }\end{array}$ \\
\hline GHG & Greenhouse Gas \\
\hline GHGP & Greenhouse Gas Protocol \\
\hline HEIs & Higher Education Institutions \\
\hline $\mathrm{HFC}$ & Hydrofluorocarbons \\
\hline ICAO & International Civil Aviation Organisation \\
\hline ICONTEC & $\begin{array}{l}\text { Instituto Colombiano de Normas Técnicas y Certificación } \\
\text { (Colombian Institute of Technical Standards and Certification) }\end{array}$ \\
\hline IPCC & Intergovernmental Panel on Climate Change \\
\hline ISO & International Organisation for Standardization \\
\hline ISO14064 & Greenhouse Gases Emissions Package \\
\hline NTC & $\begin{array}{l}\text { Norma Técnica Colombiana } \\
\text { (Colombian Technical Standard) }\end{array}$ \\
\hline NTC ISO & Colombian Technical Standard based on ISO standard \\
\hline SDG & Sustainable Development Goal \\
\hline UPB & Universidad Pontificia Bolivariana \\
\hline UPME & $\begin{array}{l}\text { Unidad de Planeación Minero Energética } \\
\text { (Mining and Energy Planning Unit) }\end{array}$ \\
\hline WBCSD & World Business Council for Sustainable Development \\
\hline WFLDB & World Food LCA Database \\
\hline WRI & World Resources Institute \\
\hline
\end{tabular}

\section{References}

1. United Nations. The Sustainable Development Goals Report 2020; Technical Report; United Nations Publications: New York, NY, USA, 2020.

2. O'Neill, D.W.; Fanning, A.L.; Lamb, W.F.; Steinberger, J.K. A good life for all within planetary boundaries. Nat. Sustain. 2018, 1, 88-95. [CrossRef]

3. Li, M.; Wiedmann, T.; Fang, K.; Hadjikakou, M. The role of planetary boundaries in assessing absolute environmental sustainability across scales. Environ. Int. 2021, 152, 106475. [CrossRef] [PubMed]

4. Hacking, T. The SDGs and the sustainability assessment of private-sector projects: theoretical conceptualisation and comparison with current practice using the case study of the Asian Development Bank. Impact Assess. Proj. Apprais. 2019, 37, 2-16. [CrossRef]

5. Horn, P.; Grugel, J. The SDGs in middle-income countries: Setting or serving domestic development agendas? Evidence from Ecuador. World Dev. 2018, 109, 73-84. [CrossRef]

6. Fukuda-Parr, S.; Muchhala, B. The Southern origins of sustainable development goals: Ideas, actors, aspirations. World Dev. 2020, 126, 104706. [CrossRef]

7. James, P. Urban Sustainability in Theory and Practice: Circles of Sustainability; Advances in Urban Sustainability, Routledge: New York, NY, USA, 2015.

8. Desouza, K.C.; Flanery, T.H. Designing, planning, and managing resilient cities: A conceptual framework. Cities 2013, 35, 89-99. [CrossRef]

9. Storey, M.; Killian, S.; O'Regan, P. Responsible management education: Mapping the field in the context of the SDGs. Int. J. Manag. Educ. 2017, 15, 93-103. [CrossRef]

10. Mawonde, A.; Togo, M. Implementation of SDGs at the University of South Africa. Int. J. Sustain. High. Educ. 2019, 20, 932-950. [CrossRef]

11. Leal Filho, W. Non-conventional learning on sustainable development: achieving the SDGs. Environ. Sci. Eur. 2021, 33, 1-4. [CrossRef] 
12. Paletta, A.; Bonoli, A. Governing the university in the perspective of the United Nations 2030 Agenda: The case of the University of Bologna. Int. J. Sustain. High. Educ. 2019, 20, 500-514. [CrossRef]

13. Weber, S.; Newman, J.; Hill, A. Ecological regional analysis applied to campus sustainability performance. Int. J. Sustain. High. Educ. 2017, 18, 974-994. [CrossRef]

14. Pauer, S.U.; Pilon, A.; Badelt, B. Strengthening city-university partnerships to advance sustainability solutions: A study of research collaborations between the University of British Columbia and City of Vancouver. Int. J. Sustain. High. Educ. 2020, 21, 1189-1208. [CrossRef]

15. Agostino, D.; Dal Molin, M. A grid approach to managing sustainability: evidence from a multiple Italian case study. Int. J. Sustain. High. Educ. 2016, 17, 875-894. [CrossRef]

16. Velasco, A.; Valencia, M.; Morrow, S.; Ochoa-Herrera, V. Understanding the limits of assessing sustainability at Universidad San Francisco de Quito USFQ, Ecuador, while reporting for a North American system. Int. J. Sustain. High. Educ. 2018, 19, 721-738. [CrossRef]

17. Aleixo, A.M.; Leal, S.; Azeiteiro, U.M. Conceptualization of sustainable higher education institutions, roles, barriers, and challenges for sustainability: An exploratory study in Portugal. J. Clean. Prod. 2018, 172, 1664-1673. [CrossRef]

18. Drahein, A.D.; De Lima, E.P.; Da Costa, S.E.G. Sustainability assessment of the service operations at seven higher education institutions in Brazil. J. Clean. Prod. 2019, 212, 527-536. [CrossRef]

19. Barros, M.V.; Puglieri, F.N.; Tesser, D.P.; Kuczynski, O.; Piekarski, C.M. Sustainability at a Brazilian university: Developing environmentally sustainable practices and a life cycle assessment case study. Int. J. Sustain. High. Educ. 2020, 21, 841-859. [CrossRef]

20. Son-Turan, S.; Lambrechts, W. Sustainability disclosure in higher education: A comparative analysis of reports and websites of public and private universities in Turkey. Int. J. Sustain. High. Educ. 2019, 20, 1143-1170. [CrossRef]

21. Abu Qdais, H.; Saadeh, O.; Al-Widyan, M.; Al-tal, R.; Abu-Dalo, M. Environmental sustainability features in large university campuses: Jordan University of Science and Technology (JUST) as a model of green university. Int. J. Sustain. High. Educ. 2019, 20, 214-228. [CrossRef]

22. Hernández-Diaz, P.M.; Polanco, J.A.; Escobar-Sierra, M.; Filho, W.L. Holistic integration of sustainability at universities: Evidences from Colombia. J. Clean. Prod. 2021, 305, 127145. [CrossRef]

23. Rauch, J.N.; Newman, J. Defining sustainability metric targets in an institutional setting. Int. J. Sustain. High. Educ. 2009, 10, 107-117. [CrossRef]

24. Amaral, L.P.; Martins, N.; Gouveia, J.B. Quest for a sustainable university: A review. Int. J. Sustain. High. Educ. 2015, 16, 155-172 [CrossRef]

25. Leal Filho, W.; Pallant, E.; Enete, A.; Richter, B.; Brandli, L.L. Planning and implementing sustainability in higher education institutions: An overview of the difficulties and potentials. Int. J. Sustain. Dev. World Ecol. 2018, 25, 712-720. [CrossRef]

26. Vargas, L.; Mac-Lean, C.; Huge, J. The maturation process of incorporating sustainability in universities. Int. J. Sustain. High. Educ. 2019, 20, 441-451. [CrossRef]

27. Leal Filho, W.; Will, M.; Salvia, A.L.; Adomßent, M.; Grahl, A.; Spira, F. The role of green and Sustainability Offices in fostering sustainability efforts at higher education institutions. J. Clean. Prod. 2019, 232, 1394-1401. [CrossRef]

28. Roos, N.; Guenther, E. Sustainability management control systems in higher education institutions from measurement to management. Int. J. Sustain. High. Educ. 2020, 21, 144-160. [CrossRef]

29. van Soest, H.L.; den Elzen, M.G.J.; van Vuuren, D.P. Net-zero emission targets for major emitting countries consistent with the Paris Agreement. Nat. Commun. 2021, 12, 1-9. [CrossRef] [PubMed]

30. O'Hara, M.E.; Sirianni, P. Carbon efficiency of US colleges and universities: a nonparametric assessment. Appl. Econ. 2016, 49, 1083-1097. [CrossRef]

31. Jain, S.; Agarwal, A.; Jani, V.; Singhal, S.; Sharma, P.; Jalan, R. Assessment of carbon neutrality and sustainability in educational campuses (CaNSEC): A general framework. Ecol. Indic. 2017, 76, 131-143. [CrossRef]

32. Fonseca, P.; Moura, P.; Jorge, H.; de Almeida, A. Sustainability in university campus: Options for achieving nearly zero energy goals. Int. J. Sustain. High. Educ. 2018, 19, 790-816. [CrossRef]

33. Udas, E.; Wölk, M.; Wilmking, M. The "carbon-neutral university"-A study from Germany. Int. J. Sustain. High. Educ. 2018, 19, 130-145. [CrossRef]

34. Yangka, D.; Rauland, V.; Newman, P. Carbon neutral policy in action: The case of Bhutan. Clim. Policy 2018, 19, 672-687. [CrossRef]

35. Auger, C.; Hilloulin, B.; Boisserie, B.; Thomas, M.; Guignard, Q.; Rozière, E. Open-Source Carbon Footprint Estimator: Development and University Declination. Sustainability 2021, 13, 4315. [CrossRef]

36. Li, Z.; Chen, Z.; Yang, N.; Wei, K.; Ling, Z.; Liu, Q.; Chen, G.; Ye, B.H. Trends in research on the carbon footprint of higher education: A bibliometric analysis (2010-2019). J. Clean. Prod. 2021, 289, 125642. [CrossRef]

37. Helmers, E.; Chang, C.C.; Dauwels, J. Carbon footprinting of universities worldwide: Part I—objective comparison by standardized metrics. Environ. Sci. Eur. 2021, 33, 1-25. [CrossRef]

38. Moerschbaecher, M.; Day, J.W. The Greenhouse Gas Inventory of Louisiana State University: A Case Study of the Energy Requirements of Public Higher Education in the United States. Sustainability 2010, 2, 2117-2134. [CrossRef] 
39. Zhao, W.; Zou, Y. Green university initiatives in China: A case of Tsinghua University. Int. J. Sustain. High. Educ. 2015, 16, 491-506. [CrossRef]

40. Lambert, M.; Cushing, K.K. How low can you go? Understanding ecological footprint reduction in university students, faculty and staff. Int. J. Sustain. High. Educ. 2017, 18, 1142-1156. [CrossRef]

41. Ortegon, K.; Acosta, P. Ecological footprint: A tool for environmental management in educational institutions. Int. J. Sustain. High. Educ. 2019, 20, 675-690. [CrossRef]

42. Genta, C.; Favaro, S.; Sonetti, G.; Barioglio, C.; Lombardi, P. Envisioning green solutions for reducing the ecological footprint of a university campus. Int. J. Sustain. High. Educ. 2019, 20, 423-440. [CrossRef]

43. Orenstein, D.E.; Troupin, D.; Segal, E.; Holzer, J.M.; Hakima-Koniak, G. Integrating ecological objectives in university campus strategic and spatial planning: A case study. Int. J. Sustain. High. Educ. 2019, 20, 190-213. [CrossRef]

44. Sima, M.; Grigorescu, I.; Bălteanu, D. An overview of campus greening initiatives at universities in Romania. Int. J. Sustain. High. Educ. 2019, 20, 410-422. [CrossRef]

45. Jarillo, P.; Pedraza.; Ger.; Bocos. Challenges of Online Higher Education in the Face of the Sustainability Objectives of the United Nations: Carbon Footprint, Accessibility and Social Inclusion. Sustainability 2019, 11, 5580. [CrossRef]

46. Mendoza-Flores, R.; Quintero-Ramírez, R.; Ortiz, I. The carbon footprint of a public university campus in Mexico City. Carbon Manag. 2019, 10, 501-511. [CrossRef]

47. Clabeaux, R.; Carbajales-Dale, M.; Ladner, D.; Walker, T. Assessing the carbon footprint of a university campus using a life cycle assessment approach. J. Clean. Prod. 2020, 273, 122600. [CrossRef]

48. Varón-Hoyos, M.; Osorio-Tejada, J.; Morales-Pinzón, T. Carbon footprint of a university campus from Colombia. Carbon Manag. 2021, 12, 1-15. [CrossRef]

49. Aristizábal-Alzate, C.E.; González-Manosalva, J.L. Application of NTC-ISO 14064 standard to calculate the Greenhouse Gas emissions and Carbon Footprint of ITM's Robledo campus. Dyna 2021, 88, 88-94. [CrossRef]

50. Bataille, C.; Waisman, H.; Briand, Y.; Svensson, J.; Vogt-Schilb, A.; Jaramillo, M.; Delgado, R.; Arguello, R.; Clarke, L.; Wild, T.; et al. Net-zero deep decarbonization pathways in Latin America: Challenges and opportunities. Energy Strategy Rev. 2020, 30, 100510. [CrossRef]

51. Delgado, R.; Wild, T.B.; Arguello, R.; Clarke, L.; Romero, G. Options for Colombia's mid-century deep decarbonization strategy. Energy Strategy Rev. 2020, 32, 100525. [CrossRef]

52. Eggleston, H.; Buendia, L.; Miwa, K.; Nagara, T.; Tanabe, K. 2006 IPCC Guidelines for National Greenhouse Gas Inventories; Technical Report Prepared by the National Greenhouse Gas Inventories Programme; Institute for Global Environmental Strategies: Hayama, Japan, 2006.

53. Myhre, G.; Shindell, D.; Bréon, F.M.; Collins, W.; Fuglestvedt, J.; Huang, J.; Koch, D.; Lamarque, J.F.; Lee, D.; Mendoza, B.; et al. Climate Change 2013: The Physical Science Basis. Contribution of Working Group I to the Fifth Assessment Report of the Intergovernmental Panel on Climate Change; Cambridge University Press: Cambridge, UK, 2013; pp. 659-740.

54. U.S. EPA. Greenhouse Gas Emissions Estimation Methodologies for Biogenic Emissionsfrom Selected Source Categories: Solid Waste Disposal, Wastewater Treatment and Ethanol Fermentation; Technical Report EP-D-06-118; RTI International for U.S. Environmental Protection Agency: Washington, DC, USA, 2010.

55. U.S. EPA. Waste Reduction Model (WARM)-Composting; Technical Report Version 13; U.S. Environmental Protection Agency: Washington, DC, USA, 2015.

56. UPME. Consultoría Técnica Para el Fortalecimiento y Mejora de la Base de Datos de Factores de Emisión de los Combustibles ColombianosFECOC; Technical Report FECOC2016; Incombustión para Unidad de Planeación Minero Energética (UPME): Medellin, Colombia, 2016.

57. AMVA. Actualización Inventario de Emisiones Atmosféricas del Valle de Aburrá-Año 2015; Technical Report; Area Metropolitana del Valle de Aburra (AMVA): Medellin, Colombia, 2017.

58. UK DBEIS. 2019 Government GHG Conversion Factors for Company Reporting; Technical Report; UK Department for Business, Energy and Industrial Strategy: London, UK, 2019.

59. Nemecek, T.; Bengoa, X.; Lansche, J.; Roesch, A.; Faist-Emmenegger, M.; Rossi, V.; Humbert, S. Methodological Guidelines for the Life Cycle Inventory of Agricultural Products, 3th ed.; Quantis and Agroscope-World Food LCA Database (WFLDB): Zurich, Switzerland, 2019.

60. UPME. Cálculo del Factor de Emisiones de la Red de Energía Eléctrica en Colombia; Technical Report F-DI-01-V4; Unidad de Planeación Minero Energética (UPME): Bogotá, Colombia, 2020.

61. Environmental Paper Network. Paper Calculator Version 4.0. Available online: www.papercalculator.org (accessed on December 2019).

62. International Civil Aviation Organization. ICAO Carbon Emissions Calculator. 2021. Available online: https://www.icao.int/ environmental-protection/CarbonOffset/Pages/default.aspx (accessed on December 2019).

63. Bhatia, P.; Ranganathan, J. The Greenhouse Gas Protocol: A Corporate Accounting and Reporting Standard, Revised ed.; World Resources Institute: Washington, DC, USA, 2004.

64. ISO. Greenhouse gases-Part 1: Specification with Guidance at the Organization Level for Quantification and Reporting of Greenhouse Gas Emissions and Removals; Standard ISO 14064-1:2006; ISO-International Organization for Standardization: London, UK, 2006. 
65. UPB. Sustainability Report Multicampus UPB 2020, GRI Methodology-Global Reporting Initiative-GRI; Universidad Pontificia Bolivariana: Medellín, Colombia, 2020.

66. Thomas, S. Greenhouse Gas Emissions Report; Altern Consult for Renault Trucks SAS: Lyon, France, 2012.

67. Serrano-Tierz, A.; Iturbe, A.M.; Muñoz, Ó.G.; Sáenz, J.L.S. Análisis de ahorro energético en iluminación LED industrial: Un estudio de caso. Dyna 2015, 82, 231-239. [CrossRef]

68. UNEP. Accelerating the Global Adoption of Engergy-Efficient Lighting. Technical Report. 2017. Available online: https: / / united4efficiency.org/resources/publications / (accessed December 2019).

69. INSHT. Guía Técnica para la Evaluación y Prevención de los Riesgos Relativos a la Utilización de los Lugares de Trabajo. Technical Report GT.104.1.15 NIPO 272-15-042-2. 2015. Available online: https:/ / www.insst.es/documentacion/catalogo-de-publicaciones (accessed December 2019). 